\title{
Continued versus interrupted aspirin use and bleeding risk after endoscopic submucosal dissection of gastric neoplasms: a meta-analysis
}

\author{
Veeravich Jaruvongvanich ${ }^{\mathrm{a}, \mathrm{b}}$, Tomoki Sempokuyaa ${ }^{a}$, Karn Wijarnpreechac, Patompong Ungprasert ${ }^{\mathrm{d}}$ \\ University of Hawaii, Honolulu, HI, USA; King Chulalongkorn Memorial Hospital, Bangkok, Thailand; Bassett Medical \\ Center and Columbia University College of Physicians and Surgeons, Cooperstown, NY, USA; Mahidol University, \\ Bangkok, Thailand
}

\section{Abstract}

Departments of anternal Medicine, University of Hawaii, Honolulu, HI, USA (Veeravich Jaruvongvanich, Tomoki Sempokuya);

${ }^{\mathrm{b}}$ Medicine, King Chulalongkorn Memorial Hospital, Bangkok, Thailand (Veeravich Jaruvongvanich); 'Internal Medicine, Bassett Medical Center and Columbia University College of Physicians and Surgeons, Cooperstown, NY, USA (Karn Wijarnpreecha); ${ }^{\mathrm{D} D i v i s i o n}$ of Clinical Epidemiology, Siriraj Medical Research Center, Faculty of Medicine Siriraj Hospital, Mahidol University, Bangkok, Thailand (Patompong Ungprasert)

\section{Conflict of Interest: None}

Correspondence to: Veeravich Jaruvongvanich, MD, Department of Internal Medicine, University of Hawaii, Honolulu, HI, 96817 USA, e-mail: veeravich_j@hotmail.com

Received 21 November 2017; accepted 22 December 2017; published online 15 March 2018

DOI: https://doi.org/10.20524/aog.2018.0251

\section{Introduction}

Stomach cancer is a major public health issue, as it is the fourth most common cancer in the world [1]. Endoscopic submucosal dissection (ESD) is an advanced technique used to remove superficial gastric neoplasms [2]. It provides a higher rate of en bloc resection and a lower rate of cancer recurrence compared to an endoscopic mucosal resection [3]. The National Comprehensive Cancer Network recommends ESD because of its therapeutic potential in early gastric cancer in addition to the diagnostic information it provides [4]. Postprocedural bleeding is one of the most common complications of ESD, with a reported incidence of $5.1 \%$ [5].

Aspirin is one of the most commonly prescribed medications worldwide. It is used for the treatment and prevention of several cardiovascular diseases, including ischemic stroke, myocardial infarction, and peripheral arterial disease [6]. According to a 
recent report, low-dose aspirin is used for either primary or secondary cardiovascular disease prevention in about $30 \%$ of the United States adult population [7]. Balancing the bleeding and thromboembolic risks for patients who use aspirin and need to undergo an invasive procedure with a high risk of bleeding, such as ESD, is a delicate process. The recommendations regarding the periprocedural management of aspirin vary considerably across the guidelines from different national associations. For instance, the American Society of Gastrointestinal Endoscopy recommends continuing aspirin periprocedurally, regardless of thrombotic risks [8], whereas the European Society of Gastrointestinal Endoscopy recommends that aspirin discontinuation should be considered for patients whose risk of hemorrhage outweighs the risk of thrombotic events [9]. The Japan Gastroenterological Endoscopy Society recommends continuation of aspirin in patients with high thrombotic risk and discontinuation of aspirin for 3-5 days in patients with low thrombotic risk [10]. The aim of this systematic review and meta-analysis is to evaluate the risk of post-ESD bleeding among patients who continue aspirin compared to those who discontinue aspirin prior to the procedure.

\section{Materials and methods}

\section{Search strategy}

Two authors (PU and VJ) independently searched published articles indexed in Ovid/MEDLINE and EMBASE databases from inception to August 2017 using a search strategy that comprised the terms for "aspirin" and "endoscopic submucosal dissection", as detailed in Supplementary Table 1. No language restriction was applied. Reviews, case reports, and letters were excluded. References of selected retrieved articles were also reviewed manually.

\section{Eligibility criteria}

We included observational studies that met the following inclusion criteria: 1 ) adult patients ( $\geq 18$ years of age) with gastric neoplasms; 2) undergoing gastric endoscopic submucosal dissection; 3) aspirin was stopped prior to the procedure in one group of patients, while the other group continued aspirin periprocedurally; and 4) the number of bleeding events and thrombotic events after the procedure were reported in both groups.

Two authors (PU and VJ) independently reviewed and evaluated the eligibility of the retrieved articles. The quality of each study was also independently evaluated by the same two authors using the Newcastle-Ottawa quality assessment scale, which assessed each study in three areas, including: i) the selection of the study subjects; ii) the comparability of the groups; and iii) the ascertainment of the outcome of interest [11]. Any difference in the determination of the eligibility of each study was resolved by conference with all authors.

\section{Data extraction}

The following data were abstracted from each study using a standardized study record form: first author name, study location, year of publication, study design, number of participants, participants' baseline characteristics, aspirin interruption strategy, number of bleeding events, and number of thrombotic events. The data were extracted independently by the same two authors to ensure accuracy.

\section{Statistical analysis}

Point estimates and standard errors from individual studies were combined using the generic inverse variance method of DerSimonian and Laird, which assigned the weight of each study based on its variance [12]. In light of the high likelihood of between-study variance, a randomeffect model was used. The heterogeneity of effect size estimates across the studies was quantified using the $Q$ statistic and $I^{2}(\mathrm{P}<0.10$ was considered significant $)$. A value of $\mathrm{I}^{2}$ of $0-25 \%$ indicates insignificant heterogeneity, 26-50\% low heterogeneity, 51-75\% moderate heterogeneity, and 76-100\% high heterogeneity [13]. Publication bias was assessed using a funnel plot [14]. Data analysis was performed using Review Manager 5.3 software from the Cochrane Collaboration (London, United Kingdom).

\section{Results}

The initial search yielded 3929 potentially relevant articles (2383 articles from EMBASE and 1546 articles from MEDLINE). After the exclusion of 1508 duplicated articles, 2421 articles underwent title and abstract review. A total of 2387 articles were excluded at this stage, as they clearly did not fulfill the eligibility criteria, leaving 34 articles for fulllength review. Twenty-nine articles were excluded after the full-length review, for the following reasons: 7 studies were reviews, case reports, or letters; 4 studies did not perform ESD; 6 studies performed ESD outside the stomach; 7 studies did not recruit our subjects of interest; and 5 studies did not report the outcome of interest. Therefore, 5 studies (all cohort studies) [15-19] that included 700 patients (266 in the aspirin-continued group and 434 in the aspirin-interrupted group) were included in the meta-analysis. Supplementary Figure 1 outlines the search methodology and study selection process. Table 1 describes the detailed characteristics and quality assessment of the included studies. Two studies are from South Korea and three studies are from Japan. The definition of post-ESD bleeding is bleeding in the interval after the procedure until 2-4 weeks postprocedurally. The aspirin interruption period ranged from 3-7 days prior to the procedure in the aspirin-interrupted group.

A significantly greater risk of post-ESD bleeding among the aspirin-continued group compared with the aspirin- 
Table 1 Characteristics of the included studies

\begin{tabular}{|c|c|c|c|c|c|}
\hline Study & Cho et al [15] & Lim et al [17] & Sanomura et al [18] & Tounou et al [19] & Igarashi et al [16] \\
\hline Country & South Korea & South Korea & Japan & Japan & Japan \\
\hline Year & 2012 & 2012 & 2014 & 2015 & 2016 \\
\hline Study design & Cohort study & Cohort study & Cohort study & Cohort study & Cohort study \\
\hline Study subjects & $\begin{array}{l}\text { Patients who took } \\
\text { daily aspirin and } \\
\text { underwent ESD for } \\
\text { EGC at the National } \\
\text { Cancer Center } \\
\text { Hospital between } \\
\text { November } 2008 \text { and } \\
\text { January } 2011\end{array}$ & $\begin{array}{l}\text { Patients who took } \\
\text { daily aspirin and } \\
\text { underwent ESD for } \\
\text { gastric neoplasms } \\
\text { at Seoul National } \\
\text { University Hospital } \\
\text { between April } 2005 \\
\text { and April } 2010\end{array}$ & $\begin{array}{l}\text { Patients who took } \\
\text { daily aspirin and } \\
\text { underwent ESD for } \\
\text { EGC at Hiroshima } \\
\text { University Hospital } \\
\text { between April } 2005 \\
\text { and June } 2012\end{array}$ & $\begin{array}{l}\text { Patients who took } \\
\text { daily aspirin and } \\
\text { underwent ESD for } \\
\text { gastric neoplasms } \\
\text { at Shin-Tokyo } \\
\text { Hospital between } \\
\text { January } 2007 \text { and } \\
\text { July } 2013\end{array}$ & $\begin{array}{l}\text { Patients who } \\
\text { took daily aspirin } \\
\text { and underwent } \\
\text { ESD for gastric } \\
\text { neoplasms at } \\
\text { Shizuoka Cancer } \\
\text { Center between } \\
\text { January } 2009 \text { and } \\
\text { October } 2014\end{array}$ \\
\hline $\begin{array}{l}\text { Definition of } \\
\text { postprocedural } \\
\text { bleeding }\end{array}$ & $\begin{array}{l}\text { Fall in } \mathrm{Hgb} \text { of } \\
\text { at least } 2 \mathrm{~g} / \mathrm{dL} \\
\text { with melena or } \\
\text { hematemesis that } \\
\text { occurred within } \\
4 \text { weeks after ESD }\end{array}$ & $\begin{array}{l}\text { Fall in } \mathrm{Hgb} \text { of at } \\
\text { least } 2 \mathrm{~g} / \mathrm{dL}, \mathrm{GIB} \text {, } \\
\text { or requirement } \\
\text { of endoscopic } \\
\text { hemostasis that } \\
\text { occurred within } \\
2 \text { weeks after ESD }\end{array}$ & $\begin{array}{l}\text { Fall in } \mathrm{Hgb} \text { of at } \\
\text { least } 2 \mathrm{~g} / \mathrm{dL} \text {, melena } \\
\text { or hematemesis }\end{array}$ & $\begin{array}{l}\text { Hematemesis, } \\
\text { melena or } \\
\text { hypotension } \\
\text { confirmed with } \\
\text { urgent endoscopy } \\
\text { that occurred } \\
\text { within } 4 \text { weeks after } \\
\text { ESD }\end{array}$ & $\begin{array}{l}\text { Melena or } \\
\text { hematemesis } \\
\text { that required } \\
\text { endoscopic } \\
\text { hemostasis, which } \\
\text { occurred within } \\
4 \text { weeks after ESD }\end{array}$ \\
\hline $\begin{array}{l}\text { Average age } \\
\text { (years) }\end{array}$ & 66.8 & 62.6 & 73.7 & 71.8 & 72.4 \\
\hline Female (\%) & 25.1 & 51.8 & 17.9 & 26.6 & 22.3 \\
\hline $\begin{array}{l}\text { Continued ASA } \\
\text { users }\end{array}$ & 19 & 172 & 28 & 14 & 33 \\
\hline $\begin{array}{l}\text { Interrupted } \\
\text { ASA users }\end{array}$ & 56 & 102 & 66 & 39 & 171 \\
\hline $\begin{array}{l}\text { ASA } \\
\text { interruption } \\
\text { strategy }\end{array}$ & 7 days prior to ESD & 7 days prior to ESD & $\begin{array}{l}\text { 5-7 days prior to } \\
\text { ESD }\end{array}$ & 3 days prior to ESD & $\begin{array}{l}\text { 3-7 days prior to } \\
\text { ESD }\end{array}$ \\
\hline Dosage of ASA & N/A & N/A & LDA & LDA & N/A \\
\hline $\begin{array}{l}\text { Second-look } \\
\text { endoscopy }\end{array}$ & No & No & Yes within $24 \mathrm{~h}$ & Yes within $24 \mathrm{~h}$ & Yes within $24 \mathrm{~h}$ \\
\hline Quality of study & $\begin{array}{l}\text { Selection } 3 \text { stars } \\
\text { Comparability } 1 \\
\text { star } \\
\text { Exposure } 3 \text { stars }\end{array}$ & $\begin{array}{l}\text { Selection } 3 \text { stars } \\
\text { Comparability } 1 \text { star } \\
\text { Exposure } 3 \text { stars }\end{array}$ & $\begin{array}{l}\text { Selection } 3 \text { stars } \\
\text { Comparability } 2 \\
\text { stars } \\
\text { Exposure } 3 \text { stars }\end{array}$ & $\begin{array}{l}\text { Selection } 3 \text { stars } \\
\text { Comparability } 1 \\
\text { star } \\
\text { Exposure } 3 \text { stars }\end{array}$ & $\begin{array}{l}\text { Selection } 3 \text { stars } \\
\text { Comparability } 2 \\
\text { stars } \\
\text { Exposure } 3 \text { stars }\end{array}$ \\
\hline
\end{tabular}

ACS, acute coronary syndrome; ASA, aspirin; CVA, cerebrovascular accident; EGC, early gastric cancer; ESD, endoscopic submucosal dissection; Hgb, hemoglobin; LDA, low dose aspirin; N/A, not applicable

interrupted group was not observed in this meta-analysis, with the pooled odds ratio (OR) being 1.81 (95\% confidence interval [CI] 0.85-3.83). The statistical heterogeneity was insignificant, with an $I^{2}$ of $25 \%$ (Fig. 1). A funnel plot was used for evaluation of publication bias (Fig. 2). The plot was symmetric and did not provide suggestive evidence of publication bias, although the small number of studies may have compromised this analysis.

On the other hand, a total of 9 thrombotic events (2.1\%) occurred in the aspirin-interrupted group (6 cerebral infarction/transient ischemic attack and 3 acute coronary syndrome) whereas no thrombotic events were observed in the aspirin-continued group.

\section{Sensitivity analyses}

To confirm the robustness of the results, several sensitivity analyses were conducted. The first was performed by excluding one study at a time from the full meta-analysis to see if it had a significant influence on the result of the meta-analysis (i.e., jackknife sensitivity analysis). We found that exclusion of any study from the meta-analysis did not significantly alter the pooled result, as we continued to see that the risk of bleeding was not significantly lower or higher with continuation of aspirin (pooled OR 1.52 and 95\%CI 0.78-2.98 after exclusion of the study by Cho et al [15]; pooled OR 2.16 and 95\%CI 0.84-5.56 after exclusion of the study by Igarashi et al [16]; pooled OR 


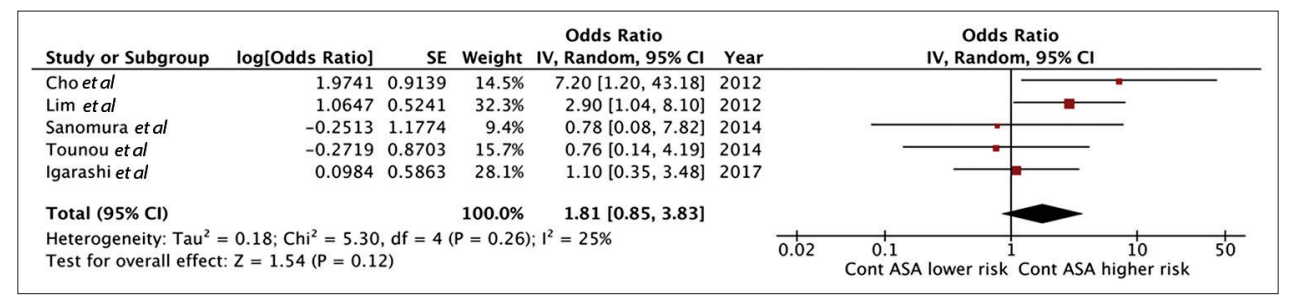

Figure 1 Forest plot of the included studies comparing the risk of bleeding between the aspirin (ASA)-continued group versus the aspirininterrupted group. A diamond data marker represents the overall odds ratio and $95 \%$ confidence interval (CI) for the outcome of interest

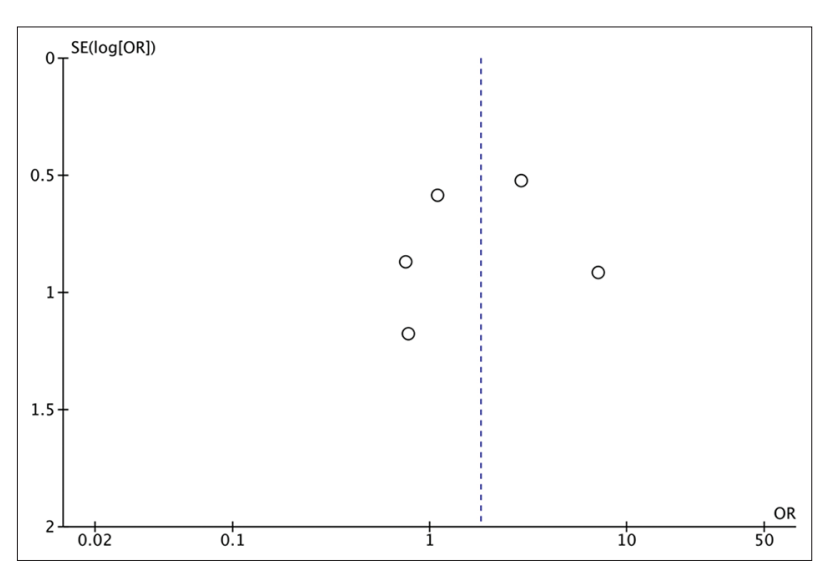

Figure 2 Funnel plot of the included studies. Circles represent observed published studies

1.45 and $95 \%$ CI $0.55-3.81$ after exclusion of the study by Lim et al [17]; pooled OR 1.98 and 95\%CI 0.84-4.62 after exclusion of the study by Sanomura et al [18]; pooled OR 2.12 and 95\%CI 0.93-4.87 after exclusion of the study by Tounou et al [19]).

The second analysis was subgroup analysis by quality of study. A total of 2 studies had a perfect Newcastle-Ottawa score of $8[16,18]$ whereas the other 3 studies each scored $7[15,17,19]$. Subgroup analysis showed a pooled OR of 1.03 (95\%CI $0.37-2.88)$ for the studies with a score of 8 and a pooled OR of 2.45 (95\%CI 0.86-7.49) for those with score of 7. The results of both subgroups were not significantly different from the full analysis.

The third analysis was subgroup analysis according to study protocol, as there were 3 studies that systematically performed second-look endoscopy on the day after ESD $[16,18,19]$ while 2 studies did not $[15,17]$. Interestingly, while the result for the subgroup of studies that systematically performed second-look endoscopy was similar to the full analysis (pooled OR 0.95; 95\%CI 0.39-2.29), subgroup analysis of the studies that did not perform second-look endoscopy showed a significantly higher risk of post-ESD bleeding among those who continued aspirin, with a pooled OR of 3.30 (95\%CI 1.49-8.85).

\section{Discussion}

With the aging of the global population, the incidence of gastric cancer and cardiovascular disease has been increasing worldwide [20]. The use of aspirin has become more prevalent, posing a challenge to clinicians to balance the risk of bleeding and the benefit of periprocedural thrombotic prevention. The current guidelines for ESD from various national associations $[7,9,6]$ provide inconsistent recommendations, as the safety of continuing aspirin periprocedurally is still not known. Our meta-analysis, which summarized all available evidence from five studies, could not demonstrate a significantly higher risk of post-ESD bleeding among patients who continued aspirin compared to those who discontinued aspirin prior to ESD.

On the other hand, interruption of low-dose aspirin use for secondary prevention is known to pose a significant risk of recurrence of cardiovascular diseases [21,22]. In this metaanalysis, we found the number of thromboembolic events was higher in the aspirin-interrupted group than the aspirincontinued group $(2.1 \%$ versus $0 \%)$. Nonetheless, it should be noted that a formal analysis to compare the incidence of thromboembolic complications between the two groups could not be performed, as no thromboembolic event occurred in the aspirin-continued group across the five included studies.

A recent meta-analysis of five studies found twofold increased odds of postprocedural bleeding in patients who continued aspirin compared to those who discontinued aspirin prior to the ESD [23]. However, the inclusion criteria for that meta-analysis were fairly broad, as it also included a study of ESD for other gastrointestinal neoplasms apart from the stomach [24]. Moreover, one included study did not compare the incidence of post-ESD bleeding between patients who continued aspirin and those who discontinued aspirin prior to ESD. That study compared the incidence of post-ESD bleeding between patients who continued aspirin and those who discontinued any antithrombotic agents prior to ESD [25]. Therefore, this study did not actually meet the eligibility criteria and should not have been included in the meta-analysis.

Whether post-ESD second-look endoscopy should be performed routinely remains controversial. The potential advantage is that endoscopists can evaluate the status of postESD ulcers and can take additional hemostatic measures if necessary [26]. Although few previous retrospective studies have reported its usefulness for prevention of delayed bleeding [27,28], subsequent randomized controlled trials failed to show any clinical benefits, including postprocedural bleeding and morbidity [29-31]. However, these trials assessed the outcomes in patients with average bleeding risk and did not specifically investigate the outcomes in patients who took aspirin. Interestingly, our meta-analysis found a significantly higher risk of post-ESD bleeding in the aspirin-continued 
group than in the aspirin-interrupted group in studies that did not routinely perform second-look endoscopy. In contrast, the risk of bleeding did not differ significantly between the groups in studies that routinely performed second-look endoscopy. This may indicate the possibility of a greater bleeding risk in the aspirin-continued group compared to the aspirininterrupted group and second-look endoscopy may reduce that risk. Whether second-look endoscopy has a role in preventing bleeding in these patients with aspirin use needs further investigation.

This meta-analysis has some limitations that may have jeopardized the validity of the results. First, although this study took advantage of the meta-analysis approach to combine all existing data, the number of included patients was still rather small. Therefore, the study could be underpowered to demonstrate any difference between the two groups. Second, all of the included studies were observational and retrospective in nature. The patients were assigned to continue or discontinue aspirin at the discretion of their endoscopists; thus, the distribution of effect modifiers/confounders may not be even between the two groups. Third, the generalizability of the results to other populations could be limited as all of the included studies were from just two Asian countries.

\section{Summary Box}

\section{What is already known:}

- Aspirin is one of the most commonly prescribed medications worldwide

- Balancing the bleeding and thromboembolic risks for patients who use aspirin and undergo gastric endoscopic submucosal dissection (ESD) is a delicate process

- The recommendations regarding the periprocedural management of aspirin vary considerably across the guidelines from different national associations

\section{What the new findings are:}

- Our meta-analysis of five studies could not demonstrate a significantly higher risk of post-ESD bleeding among patients who continued aspirin compared to those who discontinued aspirin prior to ESD

- A total of 9 thrombotic events (2.1\%) occurred in the aspirin-interrupted group whereas no thrombotic events were observed in the aspirincontinued group

- To confirm the robustness of the results, a sensitivity analysis was conducted. We found that exclusion of any study from the meta-analysis did not significantly alter the pooled result
In summary, our meta-analysis could not demonstrate that continuation of aspirin significantly increases the risk of post-ESD bleeding. However, the analysis was limited by the small sample size and the observational nature of the primary studies. Randomized controlled trials are still needed to clarify this risk.

\section{References}

1. Jemal A, Center MM, DeSantis C, Ward EM. Global patterns of cancer incidence and mortality rates and trends. Cancer Epidemiol Biomarkers Prev 2010;19:1893-1907.

2. Bhatt A, Abe S, Kumaravel A, Vargo J, Saito Y. Indications and techniques for endoscopic submucosal dissection. Am J Gastroenterol 2015;110:784-791.

3. Facciorusso A, Antonino M, Di Maso M, Muscatiello N. Endoscopic submucosal dissection vs endoscopic mucosal resection for early gastric cancer: A meta-analysis. World J Gastrointest Endosc 2014;6:555-563.

4. Ajani JA, D’Amico TA, Almhanna K, et al. Gastric cancer, Version 3.2016, NCCN Clinical Practice Guidelines in Oncology. J Natl Compr Canc Netw 2016;14:1286-1312.

5. Libânio D, Costa MN, Pimentel-Nunes P, Dinis-Ribeiro M. Risk factors for bleeding after gastric endoscopic submucosal dissection: a systematic review and meta-analysis. Gastrointest Endosc 2016;84:572-586.

6. Zusman RM, Chesebro JH, Comerota A, et al. Antiplatelet therapy in the prevention of ischemic vascular events: literature review and evidence-based guidelines for drug selection. Clin Cardiol 1999;22:559-573.

7. Stuntz M, Bernstein B. Recent trends in the prevalence of lowdose aspirin use for primary and secondary prevention of cardiovascular disease in the United States, 2012-2015. Prev Med Rep 2017;5:183-186.

8. Acosta RD, Abraham NS, Chandrasekhara V, et al. ASGE Standards of Practice Committee. The management of antithrombotic agents for patients undergoing GI endoscopy. Gastrointest Endosc 2016;83:3-16.

9. Veitch AM, Vanbiervliet G, Gershlick AH, et al. Endoscopy in patients on antiplatelet or anticoagulant therapy, including direct oral anticoagulants: British Society of Gastroenterology (BSG) and European Society of Gastrointestinal Endoscopy (ESGE) guidelines. Endoscopy 2016;48:c1.

10. Fujimoto K, Fujishiro M, Kato M, et al. Japan Gastroenterological Endoscopy Society. Guidelines for gastroenterological endoscopy in patients undergoing antithrombotic treatment. Dig Endosc 2014;26:1-14.

11. Stang A. Critical evaluation of the Newcastle-Ottawa scale for the assessment of the quality of nonrandomized studies in metaanalyses. Eur J Epidemiol 2010;25:603-605.

12. DerSimonian R, Laird N. Meta-analysis in clinical trials. Control Clin Trials 1986;7:177-188.

13. Higgins JP, Thompson SG, Deeks JJ, Altman DG. Measuring inconsistency in meta-analyses. BMJ 2003;327:557-560.

14. Sterne JA, Egger M. Funnel plots for detecting bias in meta-analysis: guidelines on choice of axis. J Clin Epidemiol 2001;54:1046-1055.

15. Cho SJ, Choi IJ, Kim CG, et al. Aspirin use and bleeding risk after endoscopic submucosal dissection in patients with gastric neoplasms. Endoscopy 2012;44:114-121.

16. Igarashi K, Takizawa K, Kakushima N, et al. Should antithrombotic therapy be stopped in patients undergoing gastric endoscopic submucosal dissection? Surg Endosc 2017;31:1746-1753. 
17. Lim JH, Kim SG, Kim JW, et al. Do antiplatelets increase the risk of bleeding after endoscopic submucosal dissection of gastric neoplasms? Gastrointest Endosc 2012;75:719-727.

18. Sanomura Y, Oka S, Tanaka S, et al. Continued use of low-dose aspirin does not increase the risk of bleeding during or after endoscopic submucosal dissection for early gastric cancer. Gastric Cancer 2014;17:489-496.

19. Tounou S, Morita Y, Hosono T. Continuous aspirin use does not increase post-endoscopic dissection bleeding risk for gastric neoplasms in patients on antiplatelet therapy. Endosc Int Open 2015;3:E31-E38.

20. Roth GA, Forouzanfar MH, Moran AE, et al. Demographic and epidemiologic drivers of global cardiovascular mortality. $N$ Engl J Med 2015;372:1333-1341.

21. Biondi-Zoccai GG, Lotrionte M, Agostoni P, et al. A systematic review and meta-analysis on the hazards of discontinuing or not adhering to aspirin among 50,279 patients at risk for coronary artery disease. Eur Heart J 2006;27:2667-2674.

22. Maulaz AB, Bezerra DC, Michel P, Bogousslavsky J. Effect of discontinuing aspirin therapy on the risk of brain ischemic stroke. Arch Neurol 2005;62:1217-1220.

23. Wu W, Chen J, Ding Q, Yang D, Yu H, Lin J. Continued use of lowdose aspirin may increase risk of bleeding after gastrointestinal endoscopic submucosal dissection: A meta-analysis. Turk $J$ Gastroenterol 2017;28:329-336.

24. Ninomiya Y, Oka S, Tanaka S, et al. Risk of bleeding after endoscopic submucosal dissection for colorectal tumors in patients with continued use of low-dose aspirin. J Gastroenterol 2015;50:1041-1046.
25. Matsumura T, Arai M, Maruoka D, et al. Risk factors for early and delayed post-operative bleeding after endoscopic submucosal dissection of gastric neoplasms, including patients with continued use of antithrombotic agents. BMC Gastroenterol 2014;14:172.

26. Kim SJ, Choi CW, Kang DH, Kim HW, Park SB. Second-look endoscopy and factors associated with delayed bleeding after endoscopic submucosal dissection. World J Gastrointest Endosc 2016;8:173-179.

27. Goto O, Fujishiro M, Kodashima S, et al. A second-look endoscopy after endoscopic submucosal dissection for gastric epithelial neoplasm may be unnecessary: a retrospective analysis of postendoscopic submucosal dissection bleeding. Gastrointest Endosc 2010;71:241-248.

28. Kim HH, Park SJ, Park MI, Moon W. Clinical impact of secondlook endoscopy after endoscopic submucosal dissection of gastric neoplasms. Gut Liver 2012;6:316-320.

29. Jee SR, Park MI, Lim SK, et al. Clinical impact of second-look endoscopy after endoscopic submucosal dissection of gastric neoplasm: a multicenter prospective randomized-controlled trial. Eur J Gastroenterol Hepatol 2016;28:546-552.

30. Mochizuki S, Uedo N, Oda I, et al. SAFE Trial Study Group. Scheduled second-look endoscopy is not recommended after endoscopic submucosal dissection for gastric neoplasms (the SAFE trial): a multicentre prospective randomised controlled noninferiority trial. Gut 2015;64:397-405.

31. Ryu HY, Kim JW, Kim HS, et al. Second-look endoscopy is not associated with better clinical outcomes after gastric endoscopic submucosal dissection: a prospective, randomized, clinical trial analyzed on an as-treated basis. Gastrointest Endosc 2013;78:285-294.

\section{Supplementary Table 1 Search strategy}

\section{Online supplementary data}

\section{Search strategy}

Database: Ovid MEDLINE

1. antiplatelet.mp.

2. aspirin.mp. or exp aspirin/

3. exp Platelet Aggregation Inhibitors/

4. or/1-3

5. endoscopic submucosal dissection.mp. or exp Endoscopic Mucosal Resection/

6. endoscopic resection.mp.

7. stomach neoplasms.mp. or exp stomach neoplasms/

8. gastric cancer.mp.

9. gastric mucosa.mp. or exp Gastric Mucosa/

10. gastric carcinoma.mp.

11. or/5-10 12. 4 and 11

Database: EMBASE

1. exp acetylsalicylic acid/or acetylsalicylic acid.mp.

2. exp antithrombocytic agent/or antithrombocytic agent.mp.

3. or/1-2

4. endoscopic submucosal dissection.mp. or exp endoscopic submucosal dissection/

5. endoscopic surgery.mp. or exp endoscopic surgery/

6. stomach tumor.mp. or exp stomach tumor/

7. stomach cancer.mp. or exp stomach cancer/

8. stomach carcinoma.mp. or exp stomach carcinoma/

9. or $/ 4-8$

10. 3 and 9 


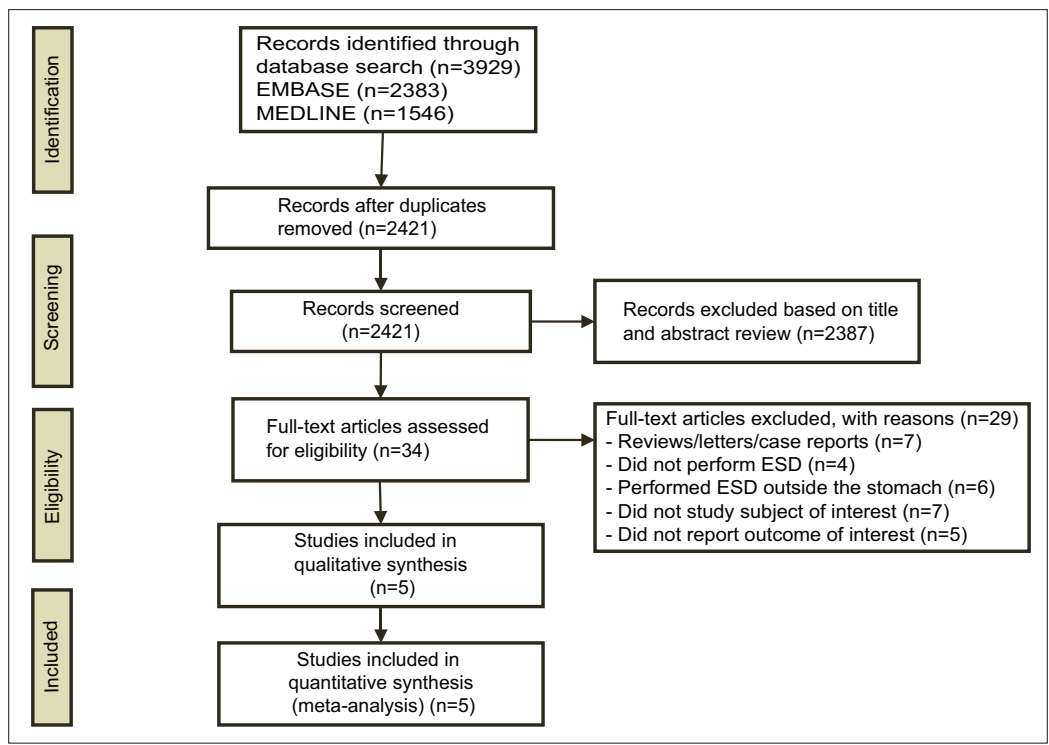

Supplementary Figure 1 Search methodology and selection process ESD, endoscopic submucosal dissection 